\title{
CONTRIBUIÇÃO DAS CAPACIDADES DINÂMICAS PARA A INOVAÇÃO SOB A LENTE DOS MICROFUNDAMENTOS
}

\section{CONTRIBUTION OF DYNAMIC CAPABILITIES FOR INNOVATION FROM THE LENS OF MICROFUNDAMENTS}

SAMUEL SOUZA AGUIAR

Universidade Feevale - Especialista em Gestão Empresarial

Orcid: http://orcid.org/0000-0001-9041-9929 / E-mail: samuelsouzaaguiar@yahoo.com.br

Endereço: Câmpus II, ERS-239, 2755 - Vila Nova - CEP.: 93525-075, Novo Hamburgo - RS.

\section{CRISTIANE FROEHLICH}

Programa de Pós-Graduação em Administração da Universidade Feevale

Doutora em Administração pela Universidade do Vale do Rio dos Sinos - UNISINOS.

Orcid: http://orcid.org/0000-0001-7198-6469 / E-mail: cristianefroehlich@hotmail.com

\section{GABRIELA ZANANDREA}

Programa de Pós-Graduação em Administração da Universidade do Vale do Rio dos Sinos - UNISINOS.

Doutora em Administração pela Universidade de Caxias do Sul.

Orcid: http://orcid.org/0000-0002-0091-0229 / E-mail: gabi.zanandrea@gmail.com

\section{CRISTINE HERMANN NODARI}

Programa de Pós-Graduação em Administração da Universidade Feevale Titulação: Doutora em Administração pela Pontifícia Universidade Católica - PUCRS Orcid: http://orcid.org/0000-0003-0397-337X / E-mail: cristinenodari@feevale.br

\section{SERJE SCHMIDT}

Programa de Pós-Graduação em Administração da Universidade Feevale Doutor em Administração pela Universidade do Vale do Rio dos Sinos - UNISINOS.

Orcid: http://orcid.org/0000-0002-5710-1828 / E-mail: serje@feevale.br

Submissão: 05/08/2019. Revisão: 21/05/2020. Aceite:11/06/2020. Publicação: 03/08/2020. DOI: http://dx.doi.org/10.22277/rgo.v13i3.5106

\section{RESUMO}

Esta pesquisa teve como objetivo verificar a contribuição das capacidades dinâmicas para a inovação, a partir da lente dos microfundamentos, utilizando o caso do parque temático de entretenimento Snowland, localizado na cidade de Gramado, no Rio Grande do Sul. De forma a compreender o objetivo delineado no estudo, relacionou-se a inovação com o modelo teórico definido por Teece (2007) composto pelas capacidades de identificar (Sensing), aproveitar (Seizing) e reconfigurar (Reconfiguring) e com o modelo de Teece, Pisano e Shuen (1997) que contempla a trajetória, posição e os processos organizacionais de uma empresa para inovação. A metodologia classifica-se em um estudo de caso, descritivo e qualitativo. Os dados foram coletados por meio de entrevistas semiestruturadas com as lideranças estratégicas e por meio de documentos da organização. Os resultados indicam que as capacidades dinâmicas contribuem para a inovação por meio das capacidades de identificação, aproveitamento e reconfiguração e seus microfundamentos, e também, por meio da análise da trajetória, posição e processos organizacionais.

Palavras-chave: Trajetória. Posição. Processos Organizacionais. Processo de Inovação. 


\begin{abstract}
This research aimed to verify the contribution of dynamic capabilities to innovation from the lens of the microfoundations, using the case of the Snowland entertainment park, located in the city of Gramado, Rio Grande do Sul. In order to understand the objective outlined in the study, innovation was related to the theoretical model defined by Teece (2007), composed by the capabilities of Sensing, Seizing and Reconfiguring, and the Teece, Pisano and Shuen (1997) model which contemplates the trajectory, position and the managerial and organizational processes of a company for innovation. The methodology is classified into a qualitative and descriptive case study. Data were collected through semi-structured interviews with strategic leaders and through organization documents. The results indicate that dynamic capabilities contribute to innovation through identification, exploitation and reconfiguring capabilities and their microfoundations, and also, through the analysis of the trajectory, position and organizational processes.
\end{abstract}

Keywords: Path. Position. Organizational Processes. Innovation Process.

\title{
1 INTRODUÇÃO
}

Ao longo dos anos as pesquisas têm se concentrado na exploração dos fatores de sucesso das organizações que se destacam nos ambientes competitivos. Para desfrutar de vantagem competitiva duradoura em um contexto caracterizado por rápidas mudanças, tornou-se essencial que as organizações não apenas se adaptem a esses ambientes, mas que desenvolvam a capacidade de inovar (HUANG et al., 2012; STRØNEN et al., 2017). A inovação se desenvolve de forma estruturada quando as organizações possuem seus processos organizacionais alinhados com as suas estratégias (TIDD; BESSANT; PAVITT, 2015). Para isso, deve-se constantemente buscar, explorar e implementar novas oportunidades nos ambientes externo e interno da empresa (BREZNIK; HISRICH, 2014). Este é justamente o foco das capacidades dinâmicas, que identificam por varredura, busca e exploração de novas ideias que atendam ao ambiente em mutação (TEECE, 2007; 2014). A exploração dessas novas ideias, quando gerenciada de forma estruturada, resulta em retornos positivos para as organizações (DASGUPTA; GUPTA, 2009). Wang e Ahmed (2007) mencionam as capacidades dinâmicas como diretamente responsáveis pelo sucesso dos negócios.

Apesar de ter um crescente número de estudos que relacionam inovação e capacidades dinâmicas, ainda permanece o desafio de entender como esta relação ocorre, uma vez que apresentam sobreposições, inconsistências e contradições (BREZNIK; HISRICH, 2014; STR $\varnothing N E N$ et al., 2017). Nesse sentido, emergem algumas pesquisas com enfoque nos microfundamentos das capacidades dinâmicas, com o intuito de avançar a compreensão dos componentes subjacentes às rotinas e capacidades e as suas interações no tempo e no espaço (FELIN et al., 2012; BATTISTI; DEAKINS, 2017; FROEHLICH; BITENCOURT; BOSSLE, 2017; FROEHLICH; BITENCOURT, 2019).

Este estudo se alia a esses esforços, pois aborda os microfundamentos que representam uma tentativa de operacionalizar as capacidades dinâmicas por meio de rotinas a partir da análise da trajetória, posição e processos organizacionais. Dessa forma, pretendese contribuir para a identificação, aproveitamento e reconfiguração das capacidades da organização no que se refere à inovação.

Diante disso, o objetivo do estudo é verificar a contribuição das capacidades dinâmicas para a inovação a partir da lente dos microfundamentos. Para isso foi realizado um estudo de 
caso no parque temático de neve Indoor - Snowland, localizado na cidade de Gramado, no Rio Grande do Sul. O parque possui 240 colaboradores e 300 indiretos, uma estrutura de 16 mil metros quadrados, com capacidade para três mil pessoas diárias (SNOWLAND, 2018). O Parque foi fundado em 2013, contudo enfrenta um desafio diário em suas atividades: a inovação constante de seus atrativos, processos de atendimento e o gerenciamento das suas atividades. Este desafio se torna difícil perante as mudanças constantes que o mercado externo impõe e com o público cada vez mais exigente. Produtos e atrações novas são esperados com maior frequência pelos seus visitantes, assim como a inovação de seus processos e o seu gerenciamento, para que suas atividades e atrações funcionem adequadamente.

\section{REFERENCIAL TEÓRICO}

O referencial teórico aborda sobre inovação e capacidades dinâmicas com intuito de explorar as relações entre os temas. Ao final, sugere-se um esquema conceitual que visa configurar de forma sistemática a relação existente entre os dois principais conceitos do estudo.

\subsection{INOVAÇÃO E CAPACIDADES DINÂMICAS}

A inovação é um processo caracterizado pela descontinuidade daquilo que está estabelecido, denominado de "destruição criativa", concebida por meio da introdução de um novo bem, da abertura de um novo mercado que proporcione ganhos econômicos (SCHUMPETER, 1934). A inovação contínua em uma organização é impulsionada pela criatividade (ALI; PETERS; LETTICE, 2012; ZHOU; HOEVER, 2014), sendo que a criatividade emerge a partir do caos (KIM; ZHONG, 2017). Nesse arranjo, Scherer e Carlomagno (2006) informam que a inovação deve ser um processo gerenciado, podendo ter seu início na criatividade e no caos, seguido por um processo estruturado, com definições de ideias, estratégias, prioridades de avaliação, e por fim, da gestão e monitoramento dos resultados.

Em síntese, o conceito de inovação possui ênfase no processo de destruição criativa; processo de dependência de trajetória; oportunidade de fazer algo diferente; implementação de algo novo ou melhoria; novo modelo de negócio e enfoque econômico (FROEHLICH, 2014). O processo de inovação assume que as empresas podem e devem usar ideias externas e internas, para alcançar os mercados e avançar na sua tecnologia. A inovação vista como uma nova estratégia possibilita a exploração de novos conhecimentos, além dos limites internos da organização. A partir disso, a cooperação com empresas e profissionais externos assume um papel essencial, e o sucesso organizacional depende da capacidade de adaptação contínua e o desenvolvimento de recursos próprios (TIDD; BESSANT; PAVITT, 2015).

Esse processo facilita a integração de conhecimentos e de aprendizagens em novos produtos, serviços e introduz inovações no mercado. Desse modo, a inovação depende da maneira como todo esse processo é conduzido, isto é, depende dos recursos, das rotinas e da capacidade de gerenciamento da organização (TIDD; BESSANT; PAVITT, 2015). Diante disso, a abordagem das capacidades dinâmicas ganha força devido a questão de mobilização de capacidades e recursos continuamente para atender as estratégias de negócios conforme o dinamismo do mercado (FROEHLICH; BITENCOURT, 2019). Teece (2007) ressalta que essa abordagem é indicada para o estudo de estratégias organizacionais, associa-se ao contexto de mudança e de inovação. 
Ainda a abordagem das capacidades dinâmicas compreende as rotinas geradas e modificadas em busca de eficiência melhorada que incluem a capacidade de perceber e em seguida, aproveitar novas oportunidades, reconfigurar e proteger ativos de conhecimentos, capacidades e ativos complementares (ZOLLO; WINTER, 2002). Além disso, permite à empresa moldar seu ambiente através da inovação e colaboração com seus clientes e outros atoreschave (TEECE, 2007; O'REILLY; TUSHMAN, 2007).

Desse modo, pode-se dizer que as capacidades dinâmicas incluem as capacidades necessárias para adaptação à mudança e oportunidades, elas ainda contribuem para o desenvolvimento da inovação na organização (FROEHLICH; BITENCOURT; BOSSLE, 2017). As capacidades dinâmicas se classificam em: Capacidade de Identificar (Sensing); Capacidade de Aproveitar (Seizing); e Capacidade de Reconfigurar (Reconfiguring) (TEECE, 2007; 2014). Subjacentes a tais capacidades estão os microfundamentos, que são "habilidades, processos, procedimentos, estruturas organizacionais, regras de decisão e disciplinas distintas" (TEECE, 2007, p. 1319), os quais servem para facilitar a operacionalidade das capacidades dinâmicas. O Quadro 1 apresenta as capacidades dinâmicas e os microfundamentos de acordo com Teece (2007; 2014).

Quadro 1 - Microfundamentos das capacidades dinâmicas

\begin{tabular}{|c|l|}
\hline Capacidades & \multicolumn{1}{c|}{ Microfundamentos } \\
\hline \multirow{3}{*}{ Sensing } & $\begin{array}{l}\text { - processos para dirigir trabalhos internos de pesquisa e desenvolvimento; } \\
\text { - processos para parcerias com fornecedores para complementar as inovações; } \\
\text { - processos para explorar desenvolvimentos científicos e tecnológicos; } \\
\text { - processos para identificação e segmentação de mercado alvo. }\end{array}$ \\
\hline \multirow{5}{*}{ Seizing } & $\begin{array}{l}\text { - soluções para clientes e o negócio; } \\
\text { - seleção das fronteiras organizacionais para garantir que a inovação traga benefícios aos } \\
\text { Reconfiguring } \\
\text { - rotinas para seleção de protocolos de tomada de decisões; } \\
\text { - rotinas para construir lealdade e comprometimento da equipe e funcionários. }\end{array}$ \\
\hline & $\begin{array}{l}\text { - descentralização e decomposição nas decisões para facilitar a capacidade de respostas } \\
\text { no atendimento dos clientes; } \\
\text { - considerados particulares na organização; } \\
\text { - governança e o gerenciamento do conhecimento para integrar o conhecimento externo } \\
\text { e interno. }\end{array}$ \\
\hline
\end{tabular}

Fonte: Adaptado de Froehlich e Bitencourt (2015).

A capacidade de identificar (Sensing) diz respeito ao conjunto de recursos que envolvem a criação de atividades visando conhecer, interagir e julgar informações sobre o ambiente de negócios, tanto interno quanto externo, que permite à organização identificar oportunidades e também, tomar decisões estratégicas sobre futuros caminhos de desenvolvimento (TEECE, 2007; 2014; TONDOLO et al., 2015; MOUSAVI; BOSSINK; VLIET, 2019).

Uma vez que uma nova oportunidade é percebida, ela deve ser explorada por meio de novos produtos, processos ou serviços. Essa capacidade é definida como capacidade de aproveitar (Seizing), consistindo na habilidade da organização em agir sobre essas oportunidades e ameaças, para ser capaz de aproveitá-las, reconfigurando os ativos tangíveis e intangíveis para enfrentar novos desafios (TEECE, 2007; 2014; TONDOLO et al., 2015; ALFORD; DUAN, 2017).

A capacidade de reconfigurar (Reconfiguring) envolve as atividades da organização necessárias para recombinar e reconfigurar os seus ativos à medida que os mercados e as tecnologias mudam. Permite manter o ajuste ao longo do tempo, auxiliando a sustentar a 
continuidade da empresa no que diz respeito ao seu ambiente, governança e gerenciamento (TEECE, 2007; 2014; ALFORD; DUAN, 2017).

A partir do exposto, acredita-se que o sucesso da inovação está intimamente ligado às capacidades dinâmicas e aos microfundamentos que as sustentam, pois tratam da capacidade de uma organização em identificar, aproveitar e reconfigurar seus ativos internos de modo a gerenciar a sua inovação, por meio das oportunidades identificadas (FROEHLICH, 2014). Diante disto, o estudo propõe o primeiro pressuposto da pesquisa (P1): As capacidades dinâmicas contribuem para a inovação por meio das capacidades de identificação, aproveitamento e reconfiguração e seus respectivos microfundamentos.

Nesse ponto, Teece, Pisano e Shuen (1997) argumentam que a vantagem competitiva das empresas reside ainda em seus processos organizacionais, moldados por sua posição de ativos e trajetórias disponíveis. $\mathrm{O}$ termo, processos organizacionais, refere-se ao modo como as atividades são realizadas na organização, suas práticas, padrões, rotinas e aprendizados (TEECE; PISANO; SHUEN, 1997; CAMISÓN; FORÉS, 2010; VIVAS-LOPEZ, 2013; FROEHLICH; BITENCOURT, 2015). Por posição entende-se como o eixo de negócios no qual a empresa atua, ou seja, o seu posicionamento estratégico (TEECE; PISANO; SHUEN, 1997). Trajetória diz respeito às alternativas estratégicas disponíveis para a empresa. As decisões estratégicas influenciam na promoção da inovação durante a trajetória (TEECE; PISANO; SHUEN, 1997; WINTER, 2003).

A partir desta fundamentação uma estrutura de processos organizacionais, posição e trajetória podem contribuir para inovação. Sendo assim, forma-se o segundo pressuposto da pesquisa (P2): As capacidades dinâmicas contribuem para inovação por meio da análise da trajetória, posição e processos organizacionais.

\subsection{ESQUEMA CONCEITUAL}

Baseado no desenvolvimento teórico apresenta-se um esquema conceitual (Figura 1) que visa configurar de forma sistemática a relação existente entre os dois principais conceitos fundamentados neste estudo.

Figura 1 - Esquema Conceitual

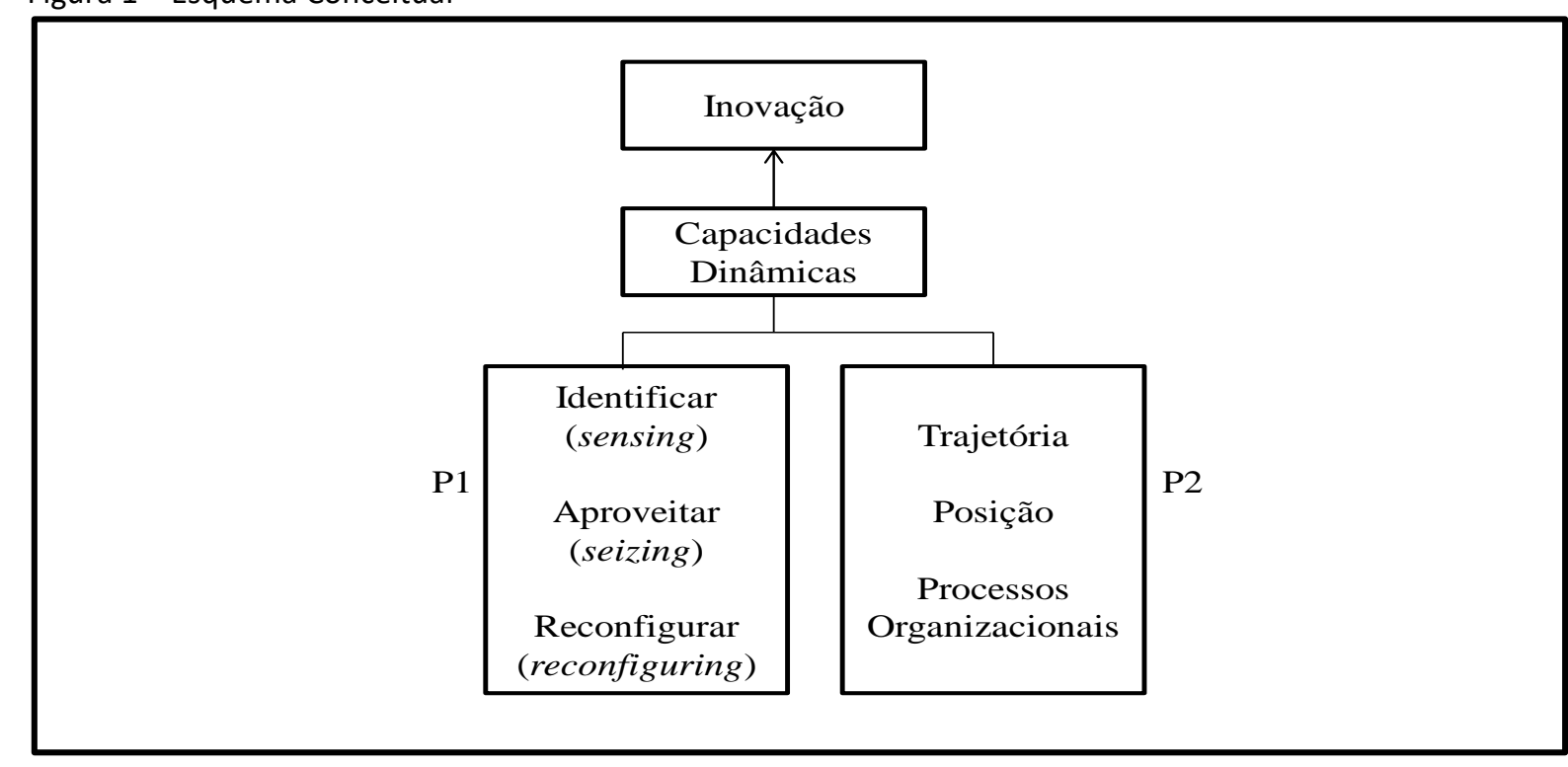

Fonte: Elaborado pelos autores. 
O esquema conceitual aborda a operacionalização das três capacidades dinâmicas identificar, aproveitar e reconfigurar - por meio dos seus respectivos microfundamentos que constituem habilidades, processos, procedimentos, estruturas e regras de decisão, necessários para o desenvolvimento e operacionalização das capacidades dinâmicas. Isso ocorre durante a trajetória da organização, a partir da definição de seu posicionamento e da consolidação de processos organizacionais. Diante disso, as capacidades dinâmicas podem contribuir para inovação.

Cabe às organizações perceberem os seus principais potenciais em sua trajetória, sua posição e seus processos, identificando-os, aproveitando-os e reconfigurando-os. Desse modo, torna-se possível a geração de novas oportunidades, novos negócios, novos produtos, serviços, novas ideias e a reformulação de seus processos para inovação.

\section{METODOLOGIA}

Para esta pesquisa foi utilizado o delineamento do estudo de caso, descritivo e qualitativo (YIN, 2015) no parque temático de neve Indoor - Snowland, fundado em outubro de 2013, localizado na região Sul do Brasil, na cidade de Gramado. O parque possui uma estrutura de 16 mil metros quadrados, com capacidade para três mil pessoas diárias, tem 240 colaboradores e 300 indiretos. A organização disponibiliza para seus usuários uma pista de patinação, simuladores de Sky, e uma montanha de neve a qual possibilita aos seus visitantes a experiência de esquiar em uma pista com neve de verdade. Lojas, cenários fotográficos, escola de patinação e castelos infantis de neve foram criados dentro de um ambiente onde a temperatura pode chegar a dez graus negativos (SNOWLAND, 2018).

Os critérios para escolha da empresa foram: a) empresa reconhecida na América do Sul, devido a sua atividade principal: proporcionar ao seu público uma experiência com neve de verdade; b) ser reconhecida no mercado e por seus colaboradores pela inovação; $c$ ) possuir em seu foco estratégico a inovação constante de suas atrações e atividades (SNOLAND, 2018).

O estudo baseou-se em dados primários coletados por meio de quatro entrevistas semiestruturadas em profundidade com um diretor, um sócio investidor e dois gerentes. Os motivos para escolha desses entrevistados é que eles ocupam os cargos estratégicos da empresa e assim poderiam contribuir com dados essenciais para a pesquisa. O Quadro 2 apresenta o perfil dos entrevistados.

Quadro 2 - Perfil dos Entrevistados

\begin{tabular}{|l|l|l|l|l|}
\hline Entrevistados & Cargo & Idade & Tempo de Empresa & Formação \\
\hline E1 & Diretor Executivo & 62 Anos & 5 anos & Administração \\
\hline E2 & Sócio Investidor & 48 Anos & 7 anos & $\begin{array}{l}\text { Administração Ênfase em } \\
\text { Marketing }\end{array}$ \\
\hline E3 & Gerente Planejamento & 35 Anos & 6 anos & Ensino Técnico \\
\hline E4 & Gerente Operações & 48 Anos & 4 anos & $\begin{array}{l}\text { Administração - Pós - } \\
\text { Gastronomia e Hotelaria }\end{array}$ \\
\hline
\end{tabular}

Fonte: Elaborado pelos autores.

Para as entrevistas foi utilizado o roteiro proposto por Froehlich (2014) em que objetiva investigar como a empresa identifica, aproveita e reconfigura oportunidades de inovação por meio da análise da trajetória, posição e processos organizacionais. As entrevistas foram gravadas com o devido consentimento dos entrevistados e, depois, transcritas para poder-se proceder com a análise. Para identificação dos entrevistados, utilizou a nomenclatura de Entrevistado (E1), Entrevistado (E2) e assim sucessivamente. Para a coleta de dados secundários foram identificados alguns documentos da organização como: 
Apresentação institucional; manuais de operações; e procedimentos internos. O Quadro 3 apresenta a síntese da pesquisa.

Quadro 3 - Síntese da Pesquisa

\begin{tabular}{|c|c|c|}
\hline Objetivo & \multicolumn{2}{|c|}{$\begin{array}{l}\text { Verificar a contribuição das capacidades dinâmicas para a inovação, a partir da lente } \\
\text { dos microfundamentos, no parque temático de entretenimento Snowland, localizado } \\
\text { na cidade de Gramado, no Rio Grande do Sul. }\end{array}$} \\
\hline Pressupostos & Categorias e Subcategorias & Autores \\
\hline $\begin{array}{c}\text { (P1): As } \\
\text { capacidades } \\
\text { dinâmicas } \\
\text { contribuem para a } \\
\text { inovação por meio } \\
\text { das capacidades de } \\
\text { identificação, } \\
\text { aproveitamento e } \\
\text { reconfiguração e } \\
\text { seus respectivos } \\
\text { microfundamentos. }\end{array}$ & $\begin{array}{l}\text { Grupos das capacidades dinâmicas e seus } \\
\text { microfundamentos: } \\
\text { a) Capacidade de identificar o contexto do ambiente } \\
\text { - Processos para dirigir trabalhos internos de pesquisa e } \\
\text { desenvolvimento; } \\
\text { - Processos para parcerias com fornecedores para } \\
\text { complementar as inovações; } \\
\text { - Processos para explorar desenvolvimentos científicos e } \\
\text { tecnológicos; } \\
\text { - Processos para identificação e segmentação de mercado } \\
\text { alvo. } \\
\text { b) Capacidade de aproveitar oportunidades } \\
\text { - Soluções para os clientes e o negócio; } \\
\text { - Seleção das fronteiras organizacionais; } \\
\text { - Rotinas para seleção de protocolos de tomada de decisão; } \\
\text { - Rotinas para construir lealdade e comprometimento. } \\
\text { c) Capacidade de gerenciar ameaças e transformações } \\
\text { - Descentralização e decomposição; } \\
\text { - Coespecialização; } \\
\text { - Governança e o gerenciamento do conhecimento. }\end{array}$ & $\begin{array}{l}\text { Teece (2007); } \\
\text { O’Reilly e Tushman } \\
\text { (2007); } \\
\text { Froehlich e Bitencourt } \\
\text { (2015); } \\
\text { Tondolo et al. (2015); } \\
\text { Silva (2016); } \\
\text { Alford e Duan (2017); } \\
\text { Mousavi, Bossink e } \\
\text { Vliet (2019). }\end{array}$ \\
\hline $\begin{array}{c}\text { (P2): As } \\
\text { capacidades } \\
\text { dinâmicas } \\
\text { contribuem para } \\
\text { inovação por meio } \\
\text { da análise da } \\
\text { trajetória, posição } \\
\text { e processos } \\
\text { organizacionais. }\end{array}$ & $\begin{array}{l}\text { Níveis das capacidades dinâmicas: } \\
\text { a) Trajetória; } \\
\text { b) Posição; } \\
\text { c) Processos organizacionais. }\end{array}$ & $\begin{array}{l}\text { Teece, Pisano e Shuen } \\
\text { (1997); } \\
\text { Priem e Butler (2001a, } \\
\text { b); } \\
\text { Winter (2003). }\end{array}$ \\
\hline
\end{tabular}

Fonte: Elaborado pelos autores.

Os dados obtidos foram analisados por meio da análise de conteúdo qualitativa que é um processo que necessita de uma sequência de atividades, envolvendo redução de dados, categorização, análise e redação do relatório (PRODANOV; FREITAS, 2013). Para isso foram considerados os pressupostos estabelecidos por Bardin (2016). Foram elaboradas três categorias a partir do referencial teórico para análise dos dados: (a) capacidade de identificar (sensing); (b) capacidade de aproveitar (seizing); e (c) capacidade de reconfigurar (reconfiguring).

\section{ANÁLISE DOS RESULTADOS}

A seção de análise apresenta os dados e análises conforme as categorias do estudo, denominadas de capacidade de identificar, capacidade de aproveitar e capacidade de reconfigurar. 


\subsection{CAPACIDADE DE IDENTIFICAR (SENSING)}

Em relação à capacidade dinâmica de identificar, o primeiro microfundamento proposto por Teece (2007) aborda processos para dirigir trabalhos internos de pesquisa e desenvolvimento. Embora não exista um departamento formal de P\&D, o Snowland fomenta a integração de suas equipes de trabalho para incentivar o desenvolvimento de melhorias de processos e novas ideias, conforme pode-se verificar por meio do relato do entrevistado (E1): "[...] ]é muito comum que as pessoas busquem coisas que já são feitas e queiram repetir rotinas, mas a gente sempre estimula para que eles pensem em novas formas de solucionar os problemas, buscando manter o DNA da empresa [...]". Nesse sentido, vale ressaltar que a inovação contínua em uma empresa é impulsionada pela criatividade que deve ser estimulada (ALI; PETERS; LETTICE, 2012; ZHOU; HOEVER, 2014).

O segundo microfundamento da capacidade de identificar está delimitado em processos para parcerias com fornecedores para complementar as inovações na organização. Neste microfundamento é possível verificar por meio dos dados secundários coletados que o parque desde sua fundação contou com processos de parcerias com colaboradores locais, como empreiteiros e construtores para o seu desenvolvimento, para a elaboração de suas máquinas e respectivamente seus produtos e atrações (SNOWLAND, 2018). Esta afirmação também é abordada pelo entrevistado (E1), o qual afirma: "[...] nós trouxemos um técnico, um profissional que tinha experiência e ele totalizou essa tecnologia, adaptou essa técnica para as nossas condições utilizando máquinas, equipamentos e prestadores de serviço brasileiros para poder desenvolver, desde então a gente continua sendo o único [...]". Nesse sentido, Tidd, Bessant e Pavitt (2015) afirmam que as empresas podem e devem usar ideias externas e internas para avançar no desenvolvimento de tecnologias e assim promover a inovação.

O terceiro microfundamento da capacidade de identificar refere-se aos processos para explorar desenvolvimentos científicos e tecnológicos (TEECE, 2007). Conforme o entrevistado (E1): "[...] a nossa inovação começou da capacidade de identificar uma tecnologia que não existia no Brasil, só lá fora, e conseguir adequar para ela funcionar aqui no Brasil com as condições que nós temos. A inovação está na essência da origem e da existência do parque $[\ldots]^{\prime \prime}$, sendo assim, a inovação está associada à dependência da trajetória (FROEHLICH, 2014). Outro exemplo deste microfundamento é o processo de criação da máquina que gera neve. Foram necessários vários experimentos para o desenvolvimento desta máquina, segundo o entrevistado (E3): "[...] nós somos o primeiro parque do mundo que tem uma queda de neve, que neva. E nós chegamos nesse nível depois de quatro anos de pesquisa e procura de uma máquina que conseguisse fazer isso [...]".

Atualmente a empresa não possui parcerias com universidades e centros de pesquisas, conforme afirmou o entrevistado (E1): "[...] está no nosso radar, mas não está implementado, a gente começou um programa de tentar se aproximar das universidades buscando estagiários, trainees e projetos que sejam contemplados [...]". Da mesma forma, o entrevistado (E3) relatou que: "[...] nós já tivemos várias pessoas, que vieram, fizeram a tese, fizeram um case, um estudo, um trabalho, mas não uma parceria fixa [...]". As parcerias com universidades e centros de pesquisa poderiam trazer vários benefícios para o parque, como novos públicos de clientes, ofertas de novos produtos e serviços por meio do desenvolvimento de novas tecnologias (TIDD; BESSANT; PAVITT, 2015).

O quarto e último microfundamento da capacidade de identificar, segundo Teece (2007), é o processo para identificação e segmentação do mercado alvo. O parque está consciente em relação a sua segmentação, segundo o entrevistado (E3): "[...] Snowland não é 
um destino, é uma atração que faz parte do destino [...]". Outra posição importante é a questão que mesmo não havendo outro parque do mesmo segmento no Brasil, o Snowland busca sua constante inovação e sua segmentação no mercado atual em que compete, tratando outras atrações e parques situados na Serra Gaúcha como concorrentes diretos. Esta forma de segmentar seu mercado alvo é ratificada pelo entrevistado (E2): "[...] ficou claro para a vida do Snow que ele nunca vai ter um ponto de "agora está pronto". Não temos concorrentes diretos, de parque de neve, mas qualquer restaurante, qualquer parque aqui é um concorrente nosso [...]".

Desta forma, entende-se por meio da análise dos microfundamentos da capacidade dinâmica de identificar (Sensing), que o parque identifica a inovação e as oportunidades associadas, contudo existem caminhos ainda a serem explorados para o aperfeiçoamento dessa capacidade, como por exemplo, a busca de parcerias externas com instituições de ensino. Diante disso, Tidd, Bessant e Pavitt (2015) reforçam a importância da cooperação como essencial para o sucesso organizacional.

\subsection{CAPACIDADE DE APROVEITAR (SEIZING)}

O primeiro microfundamento da capacidade de aproveitar se refere às soluções para os clientes e negócios (TEECE, 2007). Para isso a empresa deve explorar e buscar novos conhecimentos além dos seus limites internos (TIDD; BESSANT; PAVITT, 2015). O parque visa incorporar novos serviços aos produtos e atrações existentes. Essa necessidade de inclusão de serviços é identificada por meio de pesquisas com os clientes, que segundo O'Reilly e Tushman (2007), a colaboração com os clientes permite à empresa moldar seu ambiente por meio da promoção da inovação.

Um exemplo, se refere à reutilização de uma atração com as motoneves, as quais estavam paradas, criou-se uma forma de reutilizá-las. Conforme a colocação dos entrevistados (E1) e (E3): "[...] o motor elétrico tinha vários problemas, o principal problema era que a bateria não resistia às baixas temperaturas e descarregava muito rápido, então nós tínhamos que ter uma estrutura grande de reposição de baterias e isso acabou tornando o processo todo muito caro [...]". (E1), "[...] nós transformamos as motoneves em cenários fotográficos, as pessoas adoram tirar fotos nas motoneves e a nossa receita com fotografias é bem relevante [...]" (E3).

O segundo exemplo foi o aproveitamento da máquina de fazer neve para reformular a atração, conforme o entrevistado (E2):

[...] um bom exemplo é aquela máquina de neve, que não entregou um produto que estava legal para os nossos visitantes. Se tu queres ter um produto único, tu queres ser o diferenciado, tu tens que assumir riscos. Nós tentamos, fizemos um projeto prudente, não pegamos dinheiro e jogamos fora, foi investido num projeto bem pensado [...].

Seguindo a análise da capacidade de aproveitar, o segundo microfundamento aborda sobre a seleção das fronteiras organizacionais para garantir que a inovação traga benefícios aos seus criadores ao invés dos concorrentes (TEECE, 2007). Este microfundamento pode ser compreendido por meio do entrevistado (E3):

[...] nós como uma empresa organizada, estamos sempre procurando melhorias, estamos constantemente procurando de que maneira podemos inovar para melhorar o sistema, melhorar a experiência do público, melhorar a eficiência dos colaboradores. Quando tu procuras melhorias, não são só melhorias de bem-estar e melhorias de atratividade. Sempre procura ter melhorias econômicas para se destacar diante da concorrência [...]. 
O terceiro microfundamento apresenta as rotinas para seleção de protocolos de tomada de decisão (TEECE, 2007). Foi possível verificar que semanalmente os responsáveis pelas operações e criações, como arquitetos, engenheiros e diretores, reúnem-se para discutir e trabalhar em novos projetos, em novos produtos, e em novas atrações. O parque possui um projeto principal chamado, "parque sempre novo", que engloba vários projetos conforme o entrevistado (E3):

[...] o nome dessa reunião, um comitê que se chama "Parque Sempre Novo". É o nome da reunião. Quem está? Gerente operacional, gerente de manutenção, gerente de planejamento, diretor geral e diretor financeiro. 0 que acontece? 0 diretor operacional, traz o feedback da equipe dele. Em que coisas ele está pensando, o que precisa melhorar, o que precisa consertar [...].

Este projeto apresentado pelo entrevistado (E3), abrange mais de 170 projetos ativos que visam mudanças e melhorias para as atrações, novos produtos e serviços, e segurança do público e colaboradores. Isso demonstra que o parque possui um processo gerenciado de inovação por meio da gestão de projetos (SCHERER; CARLOMAGNO, 2006).

Por fim, apresenta-se o quarto e último microfundamento da capacidade de aproveitar, que aborda sobre as rotinas para construir lealdade e comprometimento (TEECE, 2007). Identificou-se por meio dos dados secundários que o parque possui uma política para gestão de seus colaboradores (SNOWLAND, 2018). Além disso, as ações estratégicas são realizadas para gerar comprometimento e incentivar os colaboradores para participarem ativamente das inovações (E1). Os autores Tidd, Bessant e Pavitt (2015) destacam a relevância do público interno como fonte promissora de inovações e para fomentar a cultura de inovação na organização.

\subsection{CAPACIDADE DE RECONFIGURAR (RECONFIGURING)}

Para Teece (2007) a capacidade de reconfigurar abrange as atividades necessárias para uma organização manter o ajuste ao longo do tempo e o realinhamento de seus ativos e estruturas. O primeiro microfundamento aborda a descentralização e a decomposição (TEECE, 2007).

O parque possui uma estrutura descentralizada, segundo o entrevistado 1 , formada por diretores, gerentes, líderes de equipes e a operação. Ele ainda destaca que os projetos e as sugestões de melhorias passam pela direção executiva que avalia a importância e o grau de urgência aplicando os recursos necessários para executá-los. Os colaboradores participam ativamente dos processos de melhorias e dos projetos de inovações, embora, as decisões de investimentos e a priorização dos projetos são tomadas pela direção executiva. Nesse sentido, o entrevistado (E4) falou que: "[...] junto com o (diretor executivo), a gente procura ter uma gestão mais participativa, porque você tendo as ideias surgindo dos funcionários, dos auxiliares de líderes, a chance dessa inovação ter aderência à equipe é muito mais rápida e fácil, e muito maior, com certeza [...]".

O segundo microfundamento aborda a coespecialização (TEECE, 2007). Sobre este microfundamento pode ser destacado, a partir dos dados secundários, que a organização possui capacidade de gerenciamento de ativos tecnológicos e parcerias que mobilizam e realizam a execução das mesmas. Os seus colaboradores são ativos participantes para a mobilização e realização da transformação e inovação que ocorre no parque (SNOWLAND, 2018). Desse modo, estimula-se a geração de conhecimentos e aprendizagens que podem facilitar a introdução de novas inovações (TIDD; BESSANT; PAVITT, 2015). 
O último microfundamento da capacidade de reconfigurar trata sobre a governança e o gerenciamento do conhecimento (TEECE, 2007). O parque possui alianças e parcerias que foram construídas com clientes e colaboradores. Estas alianças permitem a exploração de novos conhecimentos por meio do estabelecimento de rotinas gerenciadas (TIDD; BESSANT; PAVITT, 2015).

Contudo, conforme já apresentado anteriormente, a empresa ainda não possui parcerias consolidadas com universidades e centros de pesquisas, este processo está no radar para implantação conforme o entrevistado (E4): "[...] Ainda não. É algo que eu venho cobrando: recursos humanos; porque nós temos várias faculdades no segmento de entretenimento, de lazer, de gastronomia, educação física, aqui na região, e nós não temos parcerias com essas instituições [...]".

Mesmo não existindo uma estrutura institucionalizada para coleta e gerenciamento do conhecimento, o parque busca instigar os colaboradores para participarem, uma vez que toda e qualquer inovação pode ser gerada a partir de cada colaborador ativo no parque. Diante disso, o entrevistado (E1) abordou que:

[...] Muitas vezes o conhecimento chega através de iniciativas individuais e não institucionais, nós não temos uma busca sistemática institucionalizada por inovação. Nós temos uma série de pessoas criativas em lugares chaves que a gente dá condições para que essas pessoas possam sonhar e propor, a gente é uma empresa que tenta ouvir os criativos e tenta acreditar nos sonhos das pessoas que trabalham aqui e das pessoas que nem trabalham aqui, mas que fazem parte do nosso relacionamento, então eu acho que, apesar de não ter uma estrutura institucionalizada para obter informação de inovação, nós temos uma cultura de que 'fica com a antena ligada', ouve, abre as portas, dá oportunidade que a inovação aparece naturalmente $[\ldots] "$.

Desta forma, o parque está aprendendo a gerenciar e canalizar o seu fluxo de informações geradas por meio de seus colaboradores para aplicação em projetos. Verifica-se a partir do relato acima do entrevistado que a criatividade é estimulada, com isso é possível desenvolver a inovação de forma contínua (ALI; PETERS; LETTICE, 2012; ZHOU; HOEVER, 2014). Para otimizar e auxiliar essa atividade, o entrevistado (E4) propõe a adoção de um canal interno como o Sistema para Gerenciamento de Chamadas e Informações Internas (GLPI), organizando assim o fluxo de informações, identificando-as por categorias, áreas e respectivamente o grau de urgência sugerido. Segundo ele, com este sistema, será possível cruzar os dados gerados e reorganizá-los, de forma com que seja priorizada as informações mais indicadas através do sistema. Essa proposta não deve engessar e inibir os seus colaboradores de participarem ativamente, mas sim, institucionalizar o processo de gerenciamento do conhecimento.

Frente às evidências elencadas nos dados primários e secundários, busca-se compreender a contribuição da trajetória, posição e dos processos organizacionais para a inovação no parque. Em relação à trajetória, pode-se verificar que desde o início de suas atividades, a trajetória destaca a inovação como um elemento fundamental que está presente na sua estratégia e no seu DNA. Para Huang et al. (2012) e Strøen et al. (2017) o desenvolvimento da capacidade de inovar está associada as decisões estratégicas tomadas durante a trajetória da organização. O Snowland incluiu em sua trajetória a preocupação em renovar constantemente suas atrações e seus produtos, para que possa continuar atendendo os seus clientes com superação das expectativas. Este comportamento é devido à experiência coletada ao longo dos anos de desenvolvimento de suas atividades, a qual proporcionou ao 
parque se comunicar melhor com os seus clientes e seus colaboradores. Para o entrevistado (E1):

[...] o fato de nós sermos o único parque que oferece neve de verdade tem um valor imenso em todos os sentidos, uma coisa é o valor teórico, outra coisa é o valor prático que passa por outras condições, não basta eu ter neve de verdade e ser o único, se eu não for capaz de comunicar, de oferecer um atendimento de qualidade, se nós não tivéssemos essa característica, nós seríamos mais um parque [...].

Entende-se que o parque durante sua trajetória busca criar suas inovações para comunicar, divulgar, e oferecer os seus produtos e serviços de forma segura e organizada para as suas partes interessadas. A busca e a implementação de novas oportunidades quando gerenciada de forma estruturada resulta em retornos positivos para empresa e seus stakeholders (DASGUPTA; GUPTA, 2009; BREZNIK; HISRICH, 2014).

Em relação à posição que define o eixo de negócios no qual a empresa atua (TEECE; PISANO; SCHUEN, 1997), pode-se afirmar a partir das entrevistas que o parque se posiciona como uma empresa inovadora desde sua fundação e que a inovação percorre os níveis hierárquicos, segundo o entrevistado (E1), "[...] a inovação é um valor dessa empresa que permeia todos os níveis hierárquicos, ela começa na alta gestão, que tem que incentivar e estimular para que todos os departamentos busquem soluções inovadoras para manter o DNA da empresa [...]".

Assim como o posicionamento inovador, o parque possui dois valores que norteiam sua posição em relação ao desenvolvimento de suas atividades. É com a composição e a combinação destes três pilares, sendo a inovação, a segurança e as pessoas, que se pode afirmar que atualmente o parque busca a cada dia entregar aos seus clientes e colaboradores uma experiência inovadora com segurança, mantendo sua posição de inovar com os envolvidos nos seus processos e atividades. Desse modo, a colaboração com seus atoreschave facilita a firmação do seu posicionamento (TEECE, 2007; O'REILLY; TUSHMAN, 2007).

Para esta busca da consolidação e construção da inovação, se faz necessário compreender os processos organizacionais. O parque busca atuar e estabelecer de forma estruturada os seus processos, conforme o entrevistado (E3):

[...] a inovação faz com que nós fiquemos sempre procurando melhorias, seja em processos, estruturas, ou questões do dia a dia, ou para melhorar a eficiência de alguma questão. Para dar um exemplo, na parte de segurança, nós agora estamos implementando checklist por fase, por mais que seja algo que não é uma inovação, é uma inovação de procedimento para nós, para acrescentar à segurança do parque e melhorar o nosso monitoramento das ações que são feitas no dia a dia para abrir o parque [...].

Pode-se compreender que a estruturação dos processos é uma preocupação constante, para oferecer a segurança desejada aos envolvidos. Esta construção pode ser entendida na afirmação do entrevistado (E1):

[...] para entregar um parque seguro, nós temos que ter eficiência nos nossos procedimentos operacionais, se nós não tivermos procedimentos operacionais consolidados, estruturados, inteligentes, nós não podemos ter segurança, e esse segundo valor, a gestão do processo, processos eficientes, uma empresa organizada, uma empresa que é administrada com organização [...].

Os relatos dos entrevistados mostram que a empresa possui rotinas para o gerenciamento da questão de segurança que é um valor importante para atração e retenção dos clientes e dos colaboradores. Ainda, possuem processos para gestão do parque. De tal modo, foram constituídos processos organizacionais que constituem padrões, rotinas e 
oportunidades de aprendizados a partir dos estímulos de melhorias que podem gerar inovações (TEECE; PISANO; SHUEN, 1997; FROEHLICH; BITENCOURT, 2015).

Em resumo, pode-se compreender que por meio da análise dos níveis de trajetória, posição e processos organizacionais, verifica-se que a inovação permeia esses níveis que são aprimorados por meio dos microfundamentos das capacidades de identificar, aproveitar e reconfigurar. Desse modo, Froehlich (2014) expõe que o sucesso da inovação está ligado às capacidades dinâmicas e aos microfundamentos que as sustentam, pois tratam da capacidade de uma empresa em identificar, aproveitar e reconfigurar seus ativos de maneira a gerenciar a sua inovação durante a trajetória, que influencia na escolha do posicionamento estratégico, que demanda processos organizacionais para inovação.

Assim, resgatando o pressuposto conceitual P1, em que as capacidades dinâmicas contribuem para a inovação por meio das capacidades de identificação, aproveitamento e reconfiguração e os seus respectivos microfundamentos, pode-se identificar no estudo empírico atividades relacionadas com os microfundamentos das três capacidades propostas por Teece (2007). Atualmente o Snowland está buscando desenvolver parcerias com seus fornecedores para identificar e complementar as inovações, da mesma forma explorar o seu conhecimento interno científico para desenvolver a inovação através do seu principal produto inovador, a neve de verdade. Esse aspecto é corroborado por Camisón e Forés (2010) e VivasLopez (2013) onde destacam que os processos e rotinas organizacionais em parcerias com instituições potencializam a articulação e incorporação de novos conhecimentos científicos para a inovação. A identificação e a segmentação do seu mercado alvo apresentaram-se de forma objetiva, pois atualmente mesmo não havendo concorrentes diretos para o Snowland, pelo produto que entrega, o parque segmenta suas estratégias de mercado considerando toda e qualquer atração dentro da sua localidade como potenciais concorrentes. Por exemplo, atrações como Mini-Mundo, Mundo a Vapor, Aldeia do Papai Noel, Parque do Caracol, dentre outros. "As cidades Gramado e Canela são vizinhas e possuem várias atrações turísticas" (E3).

Para a análise de seleção de fronteiras, o estudo sugere o desenvolvimento e criação de um departamento de pesquisa e desenvolvimento, para que possa auxiliar em suas atividades e na identificação das oportunidades de inovações, bem como parcerias com universidades e centros de pesquisas para potencializar seus ativos e oportunidades internas, de forma a atender a sua seleção das fronteiras organizacionais. Ademais, conforme Camisón e Forés (2010) e Ambrosini, Bowman e Collier (2009) têm-se que as empresas devem reconhecer que a aprendizagem organizacional interna, juntamente com o desenvolvimento da capacidade de absorção intensifica a inovação, requerendo uma forte integração de sistemas internos e capacidades externas de aprendizagem dentro da perspectiva das capacidades dinâmicas.

O parque Snowland está voltado a solucionar seus problemas e atender as opiniões apresentadas por seus clientes, quando é identificada que uma atração não está correspondendo às expectativas do seu público, esta é repensada e reformulada. Estas ações fazem com que o parque construa lealdade e comprometimento, pois as soluções são construídas por meio de seus colaboradores e o estímulo de que eles podem contribuir para o desenvolvimento contínuo das inovações (ALI; PETERS; LETTICE, 2012).

A governança, o gerenciamento do conhecimento, bem como a descentralização e decomposição são desenvolvidas no parque Snowland de forma participativa, estruturas e projetos são apresentados para toda e qualquer melhoria identificada, e estas melhorias são construídas com a participação de seus colaboradores. Novamente, observam-se as contribuições de diferentes partes para reconfiguração e combinação de novas formas para o 
desenvolvimento de capacidades (ALFORD; DUAN, 2017). Sendo assim, o estudo sugere que o Snowland desenvolva parcerias com universidades e centros de pesquisas para que sua coespecialização possa ser valorizada de forma a potencializar seus ativos tecnológicos para a realização das melhorias propostas e também um processo para o gerenciamento do conhecimento.

O segundo pressuposto (P2) afirmava que as capacidades dinâmicas contribuem para inovação por meio da análise da trajetória, posição e processos organizacionais. Para tanto, foi possível identificar que o parque Snowland se posiciona como uma empresa inovadora desde a sua fundação, considerando a inovação como um valor presente nos níveis hierárquicos. Da mesma forma, além do posicionamento inovador o Snowland possui outros valores que norteiam seu posicionamento, como a segurança e as pessoas. Logo, a capacidade de inovar facilita o desenvolvimento do comportamento das pessoas e da organização para atividades e rotinas sistemáticas de inovação na empresa e consequentemente a mobilização de capacidades dinâmicas (VIVAS-LOPEZ, 2013).

Ainda relacionando a inovação com os processos organizacionais do parque, pode-se dizer que estão em constante evolução, conforme verificou-se, que a busca pela inovação ocasiona a constatação diária por melhorias em seus processos, a aplicação do checklist de verificações em suas fases, bem como o monitoramento das ações diárias que são atividades processuais constantemente revisadas por seus colaboradores. A recorrência ao desenvolvimento desses processos que incentivam a inovação vem ao encontro ao desenvolvimento das capacidades dinâmicas que dependem do tempo para provocar o desempenho almejado (PRIEM; BUTLER, 2001a, b). Por fim, a trajetória do parque, desde sua fundação, iniciou do conceito e da sua capacidade de inovar. O Snowland também incluiu em sua trajetória a preocupação em renovar constantemente seus produtos e suas atrações para que possa assim proporcionar novas expectativas a seus clientes.

\section{CONSIDERAÇÕES FINAIS}

O presente estudo buscou verificar a contribuição das capacidades dinâmicas para a inovação, a partir da lente dos microfundamentos, utilizando o caso do parque temático de entretenimento Snowland, localizado na cidade de Gramado, no Rio Grande do Sul.

Com base no estudo de caso, pode-se examinar que as capacidades dinâmicas e os seus microfundamentos contribuem para a inovação por meio da análise de como o parque identifica, aproveita e reconfigura as oportunidades de inovação relacionando com a sua trajetória, posição e os seus processos organizacionais.

Essa pesquisa pode contribuir em dois âmbitos. No âmbito acadêmico, o esquema conceitual apresentado propôs a relação existente entre as capacidades dinâmicas e a inovação, ou seja, aborda a operacionalização das três capacidades dinâmicas - identificar, aproveitar e reconfigurar - por meio dos seus respectivos microfundamentos necessários para o desenvolvimento e operacionalização das capacidades dinâmicas. A operacionalização desses microfundamentos ocorre durante a trajetória da organização, a partir da definição de seu posicionamento e da consolidação de processos organizacionais. Diante disso, as capacidades dinâmicas contribuem para inovação já que permitem a apropriação de um estoque de conhecimentos que sustentam o desenvolvimento de outras e diferentes capacidades a serem utilizadas de acordo com as escolhas estratégicas da organização.

No âmbito gerencial verificou-se a necessidade de desenvolvimento de alguns microfundamentos que podem auxiliar o parque a constituir um processo sistematizado de inovação. Sugere-se a criação de um departamento interno de P\&D com objetivo de 
Samuel Souza Aguiar, Cristiane Froehlich, Gabriela Zanandrea, Cristine Hermann Nodari e Serje Schmidt

potencializar o desenvolvimento de pesquisas e projetos de inovação. Ainda, a busca de parcerias com universidades e centros de pesquisas com intuito de identificar novas oportunidades e desenvolver conjuntamente projetos que possam ser incorporados ao parque para potencializar sua coespecialização. Para identificação de novas oportunidades e para fortalecer a lealdade e comprometimento dos colaboradores, a empresa já possui políticas de gestão de pessoas, além disso, poderia ser implementado um programa estruturado para geração de ideias, pois atualmente não existe uma estrutura institucionalizada para coleta de ideias, a empresa busca instigar informalmente seus funcionários a participarem desse processo. Por fim, a governança e o gerenciamento do conhecimento necessitam de aprimoramento de suas rotinas para obter sistematização das rotinas das suas capacidades.

Pode-se destacar como limitações do estudo que a pesquisa aplicada no parque Snowland foi direcionada somente para o nível de liderança estratégica, podendo ser ampliada para os níveis tático e operacional. A pesquisa teve como base a análise interna da direção do parque, não contemplando a análise do ambiente externo através do seu público visitante. Para novos estudos, sugere-se pesquisa com os funcionários e clientes para ampliar a percepção sobre a inovação no parque. Também uma pesquisa para verificar como o parque pode estruturar o processo de inovação de forma sistematizada para auxiliar na consolidação de seus valores organizacionais.

\section{REFERÊNCIAS}

ALFORD, P.; DUAN, Y. Understanding collaborative innovation from a dynamic capabilities' perspective. International Journal of Contemporary Hospitality Management, United Kindgdom, v. 30, n. 6, p. 2396-2416, 2017. DOI: 10.1108/IJCHM-08-2016-0426

ALI, S.; PETERS, L. D.; LETTICE, F. An organizational learning perspective on conceptualizing dynamic and substantive capabilities. Journal of Strategic Marketing, United Kingdom, v. 20, n. 7, p. 589-607, 2012. DOI: 10.1080/0965254X.2012.734845

AMBROSINI, V.; BOWMAN, C.; COLLIER, N. Dynamic capabilities: an exploration of how firms renew their resource base. British Journal of Management, United Kingdom, v. 20, p. 9-24, 2009. DOI: 10.1111/j.1467-8551.2008.00610.x

BARDIN, L. Análise de conteúdo. São Paulo: Edições, 2016.

BATTISTI, M.; DEAKINS, D. The relationship between dynamic capabilities, the firm's resource base and performance in a post-disaster environment. International Small Business Journal, California, v. 35, n. 1, p. 78-98, 2017. DOI: 10.1177/0266242615611471

BREZNIK, L.; HISRICH, R. Dynamic capabilities vs. innovation capability: are they related? Journal of Small Business and Enterprise Development, United Kingdom, v. 21, n. 3, p. 368384, 2014. DOI: https://doi.org/10.1108/JSBED-02-2014-0018

CAMISÓN, C.; FÓRES, B. Knowledge absorptive capacity: New insights for its conceptualization and measurement. Journal of Business Research, United States, v. 63, p. 707-715, 2010. DOI: 10.1016/j.jbusres.2009.04.022 
DASGUPTA, M.; GUPTA, R. Innovation in organization: a review of the role of organizational learning and knowledge management. Global Business Review, United Sates, v. 10, n. 2, p. 203-224, 2009. DOI: 10.1177/097215090901000205

FELIN, T.; FOSS, N. J.; HEIMERIKS, K. H.; MADSEN, T. L. Microfoundations of routines and capabilities: Individuals, processes, and structure. Journal of Management Studies, New Jersey, v. 49, n. 8, p. 1351-1374, 2012. DOI: 10.1111/j.1467-6486.2012.01052.x

FROEHLICH, C. O desenvolvimento da capacidade de inovação para alavancar a

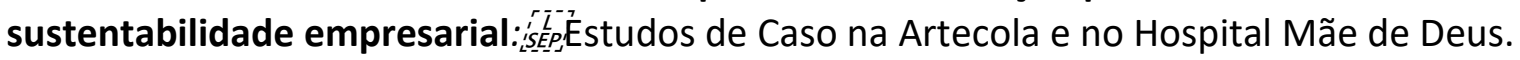
2014. 294 f. Programa de Pós-graduação em Administração Nível Doutorado. Universidade do Vale do Rio Dos Sinos - Unisinos, São Leopoldo, Rio Grande do Sul, 2014.

FROEHLICH, C.; BITENCOURT, C. C. As contribuições das capacidades dinâmicas para o desenvolvimento da capacidade de inovação: um estudo de caso na empresa Artecola Indústria Química. In: Encontro de Estudos em Estratégia da ANPAD, 7., Brasília-DF. Anais [...]. Brasília: ANPAD, 2015. Disponível em:

http://www.anpad.org.br/eventos.php?cod_evento=3\&cod_edicao_subsecao=1177\&cod_e vento_edicao=76\&cod_edicao_trabalho=18149. Acesso em: 15 mai. de 2018.

FROEHLICH, C.; BITENCOURT, C. C.; BOSSLE, M. B. The use of dynamic capabilities to boost innovation in a Brazilian Chemical Company. Revista de Administração (FEA-USP), São Paulo, v. 52, p. 479-491, 2017. DOI: 10.1016/j.rausp.2017.08.007

FROEHLICH, C.; BITENCOURT, C. C. As contribuições das capacidades dinâmicas para alavancar a inovação. In: TAKAHASHI, A. R. W.; BULGACOV, S. (Orgs). Capacidades dinâmicas e renovação estratégica: como as organizações se reinventam ao longo do tempo. Curitiba: Juruá, 2019.

HUANG, K-F.; CHURCHMAN, J.; LOWE, D. J.; RAWLENCE, N. J. How does a technological firm develop its competitive advantage? A dynamic capability perspective. IEEE Transactions on Engineering Management, United Sates, v. 59, n. 4, p. 644-653, 2012. DOI: 10.1080/10580530.2018.1440732

KIM, Y. J.; ZHONG, C-B. Ideas rise from chaos: Information structure and creativity. Organizational Behavior and Human Decision Processes, United Sates, v. 13, n. 8, p.15-27, 2017. DOI: 10.1016/j.obhdp.2016.10.001

MOUSAVI, S.; BOSSINK, B.; VLIET, M. V. Microfoundations of companies' dynamic capabilities for environmentally sustainable innovation: Case study insights from high-tech innovation in science-based companies. Business Strategy and the Environment, New Jersey, v. 28, n. 2, p. 366-387, 2019. DOI: 10.1002/bse.2255

O'REILLY, C. A.; TUSHMAN, M. L. Ambidexterity as a dynamic capability: resolving the innovator's dilemma. Research Paper Series, Stanford, p. 1-62, 2007. DOI:

10.1016/j.riob.2008.06.002 
Samuel Souza Aguiar, Cristiane Froehlich, Gabriela Zanandrea, Cristine Hermann Nodari e Serje Schmidt

PRIEM, R. L.; BUTLER, J. E. Is the reosurce-based "view" a useful perspective for strategic management research? Academy of Management Review, Chicago, v. 26, n. 1, p. 22-40, 2001a. DOI: $10.2307 / 259392$

PRIEM, R. L.; BUTLER, J. E. Tautology in the resource-based view and the implications of externally determined resource value: further comments. Academy of Management Review, Chicago, v. 26, n. 1, p. 57-66, 2001b. DOI: 10.2307/259394

PRODANOV, C. C.; FREITAS, E. C. de. Metodologia do trabalho cientifico: métodos e técnicas da pesquisa e do trabalho acadêmico. 2. ed. Novo Hamburgo: Feevale, 2013.

SCHERER, F. O.; CARLOMAGNO, M. S. Gestão da inovação na prática: como Aplicar Conceitos e Ferramentas para Alcançar a Inovação. São Paulo: Atlas, 2006.

SCHUMPETER J. A. The theory of economic development. Cambridge, Massachusetts: Harvard University Press, 1934.

SILVA, S. B. A capacidade dinâmica de "Orquestração de Redes de Inovação" no modelo de inovação aberta. Revista Alcance, Itajaí-SC, v. 23, n. 1, p. 19-33, 2016. DOI:

alcance.v23n1.p19-33

SNOWLAND PARK. Institucional. 2018. Disponível em: www.snowland.com.br. Acesso em: 20 mai. de 2018.

STR $\varnothing$ NEN, F.; HOHOLM, T.; KVAERNER, K.; ST ØME, L. N. Dynamic capabilities and innovation capabilities: the case of the innovation clinic. Journal of Entrepreneurship, New York, v. 13, n. 1 , p. $89-116,2017$. DOI: 10.7341

TEECE, D. J.; PISANO, G.; SHUEN, A. The dynamics capabilities and strategic management. Strategic Management Journal, New Jersey, v. 18, n. 7, 1997. DOI: 10.1002/(SICI)10970266(199708)18:7<509::AID-SMJ882>3.0.CO;2-Z

TEECE, D. J. Explicating dynamic capabilities: the nature and microfoundations of (sustainable) enterprise performance. Strategic Management Journal, New Jersey, v. 28, n. 13, p. 1319-1350, 2007. DOI: 10.1002/smj.640

TEECE, D. A dynamic capabilities-based entrepreneurial theory of the multinational enterprise. Journal of International Business Studies, New York, v. 45, p. 8-37, 2014. DOI: 10.1057/jibs.2013.54

TIDD, J.; BESSANT, J.; PAVITT, K. Gestão da inovação. Porto Alegre: Bookman, 2015.

TONDOLO, V. A. G.; TONDOLO, R. da R. P.; PUFFAL, D. P.; BITENCOURT, C. B. Capacidades dinâmicas e capital social organizacional: um estudo exploratório em ambiente de incubadora e parque tecnológico. Revista de Administração da UFSM, Santa Maria, v.8, n. 4, p. 666-684, 2015. DOI: 10.5902/1983465910799

VIVAS-LOPEZ, S. Implicaciones de las capacidades dinámicas para la competitividade y la innovación en el siglo XXI. Cuadernos de Administración, Bogotá, v. 26, n. 47, p. 119-139, 2013. 
WANG, C. L.; AHMED, P. K. Dynamic capabilities: a review and research. International Journal of Management Reviews, New Jersey, v. 9, p. 31-51, 2007. DOI: 10.1111/j.14682370.2007.00201.x

WINTER, S. Understanding dynamic capabilities. Strategic Management Journal, New Jersey, v. 24 , n. 10 , p. $991-995,2003$. DOI: $10.1002 /$ smj.318

YIN, R. K. Estudo de caso: planejamento e métodos. 5. ed. Porto Alegre: Bookman, 2015.

ZHOU, J.; HOEVER, I. J. Research on workplace creativity: A review and redirection. Review of Organizational Psychology and Organizational Behavior, Virginia, v. 1, n. 1, p. 333-359, 2014. DOI: 10.1146/annurev-orgpsych-031413-091226

ZOLLO, M.; WINTER, S. G. Deliberate learning and the evolution of dynamics capabilities. Organization Science, Pennsylvania, v. 13, n. 3, p. 339-351, 2002. DOI: 10.1287/orsc.13.3.339.2780 